\title{
TRANSMISSION OF LIDOCAINE HYDROCHLORIDE ACROSS THE PLACENTA DURING CAESARIAN SECTION
}

\author{
Gondon S. Fox, M.D., F.R.C.P.(c), And Germarn L. Houle, M.D., F.R.C.P.(c) ${ }^{*}$
}

SEveral REPORTs have been published on the effects of epidural analgesia upon pregnant women at delivery, and on the passage of local analgesics across the placenta. ${ }^{1-4}$ Morishima $^{1}$ and her group measured mepivacaine concentrations in the blood of mothers delivered vaginally, and in neonates after single and multiple dose epidural blockade using 1.5 per cent mepivacaine.

In 1965 Sinclair et al. ${ }^{5}$ reported on four infants intoxicated by mepivacaine inadvertently injected into the foetal scalp during caudal anaesthesia. The consequences of the unusually high concentrations of local anaesthetic were described. Recently Rosefsky and Petersiel ${ }^{6}$ examined two cases of foetal death following paracervical block. In both instances, toxic levels of the local anaesthetic were implicated as the cause of foetal death. A high rate of foetal bradycardia and depression have been noted following lidocaine paracervical blocks.

We present observations on the use of 2 per cent lidocaine hydrochloride with 1:200,000 epinephrine for lumbar epidural anaesthesia during emergency and elective caesarian sections. The maternal and foetal concentrations of lidocaine were relatively low, maternal complications were within acceptable limits, and the infants were vigorous at delivery.

\section{METHOD}

Nineteen women who received epidural analgesia for caesarian section were studied. Twelve patients had elective repeat caesarian sections and seven had emergency operations as a result of cephalopelvic disproportion. There were no other complicating features, except in case 3, a 31-year-old patient who had been treated for diabetes mellitus since the age of ten.

Premedication consisted of atropine sulphate $0.4 \mathrm{mg}$ intramuscularly one hour prior to surgery. With the patient in the sitting position, a \#16 Tuohy needle was inserted into the epidural space between the third and fourth lumbar vertebrae, using the loss of resistance technique. ${ }^{8}$ Three millilitres of sterile saline were injected through the needle to open the epidural space, and a polyvinyl catheter was inserted one needle-length cephalad. The patient was then placed in the supine position. Blood pressure was recorded using a sphygmomanometer cuff. A \#19 guage scalp vein needle was placed in a radial artery after local infiltration of the overlying skin with $0.2 \mathrm{cc}$ of 1 per cent procaine.

Samples of $5 \mathrm{ml}$ each of heparinized maternal arterial blood were taken before the injection of 2 per cent lidocaine with 1:200,000 epinephrine into the epidural space and again as the baby was delivered. The first maternal specimen was

'Royal Victoria Hospital, Montreal. 
used as a "blank" and the second to estimate lidocaine concentration at delivery. Heparinized foetal venous blood was obtained in all cases from a segment of the umbilical cord, doubly clamped prior to placental separation, and foetal arterial blood was obtained from the same segment of cord in eight cases. All blood samples were assayed for lidocaine hydrochloride by gas chromatography. ${ }^{\circ}$

Only one epidural injection of the local analgesic was given before delivery of the baby. The condition of the infant was recorded by allotting an Apgar score ${ }^{10}$ at one and five minutes after birth, and by noting the time to sustained respirations. ${ }^{11}$

The upper limit of the sensory block at the time of birth was determined by analgesia to pin-prick. The incidence of supine hypotension after the injection of lidocaine was also noted.

\section{RESULTS}

The mean maternal body weight at term, the total dose of lidocaine, and the dose of lidocaine in $\mu \mathrm{g} / \mathrm{kg}$ of body weight are shown in Table I. The mean dose of $4.50 \mathrm{mg} / \mathrm{kg}$ ( $\mathrm{sD} \pm 0.735$ ) is lower than that used by Morishima ${ }^{1}$ and her coworkers as a single injection of mepivacaine for vaginal delivery. The mean total dose of lidocaine in this study was $315.79 \mathrm{mg}$ ( $\mathrm{SD} \pm 35.9$ ). The mean dose of lidocaine in $\mathrm{mg} / \mathrm{kg}$ of body weight that we gave is of the same dose range as that used by Sinclair ${ }^{5}$ for caudal anaesthesia and Rosefsky ${ }^{6}$ for paracervical block.

Table II shows the lidocaine concentrations $(\mu \mathrm{g} / \mathrm{ml})$ in the maternal arterial blood at delivery, and in the umbilical venous and arterial blood. The maternal

TABLE I

DOSES OF LIDOCAINE USED

\begin{tabular}{lccc}
\hline \hline Case no. & $\begin{array}{c}\text { Body wt. } \\
(\mathrm{kg})\end{array}$ & $\begin{array}{c}\text { Total dose of } \\
\text { lidocaine }(\mathrm{mg})\end{array}$ & $\begin{array}{c}\text { Dose of lidocaine } \\
(\mathrm{mg} / \mathrm{kg})\end{array}$ \\
\hline 1 & 83 & 360 & 4.33 \\
2 & 88.6 & 360 & 4.10 \\
3 & 64.5 & 300 & 4.65 \\
$4(\mathrm{E})$ & 63.6 & 300 & 4.70 \\
5 & 58.2 & 320 & 5.50 \\
6 & 93.6 & 320 & 3.40 \\
7 & 55.0 & 300 & 5.45 \\
8 (E) & 67.3 & 340 & 5.05 \\
9 & 70.9 & 300 & 4.23 \\
10 (E) & 67.3 & 240 & 4.56 \\
11 & 75.0 & 300 & 5.00 \\
12 & 67.7 & 360 & 5.20 \\
13 (E) & 68.8 & 360 & 5.70 \\
$14(\mathrm{E})$ & 63.2 & 360 & 3.88 \\
15 (E) & 77.3 & 300 & 3.40 \\
16 & 95.5 & 320 & 5.00 \\
17 (E) & 64.1 & 320 & 3.88 \\
18 & 77.3 & 300 & 4.12 \\
19 & 58.2 & 240 & 4.50 \\
Mean & 71.535 & 315.79 & 0.735 \\
SD & & 35.9 & 0.169 \\
SE & & 8.23 & \\
\hline
\end{tabular}

$E=$ Emergency caesarian section.

SD = Standard deviation.

$\mathrm{SE}=$ Standard error. 


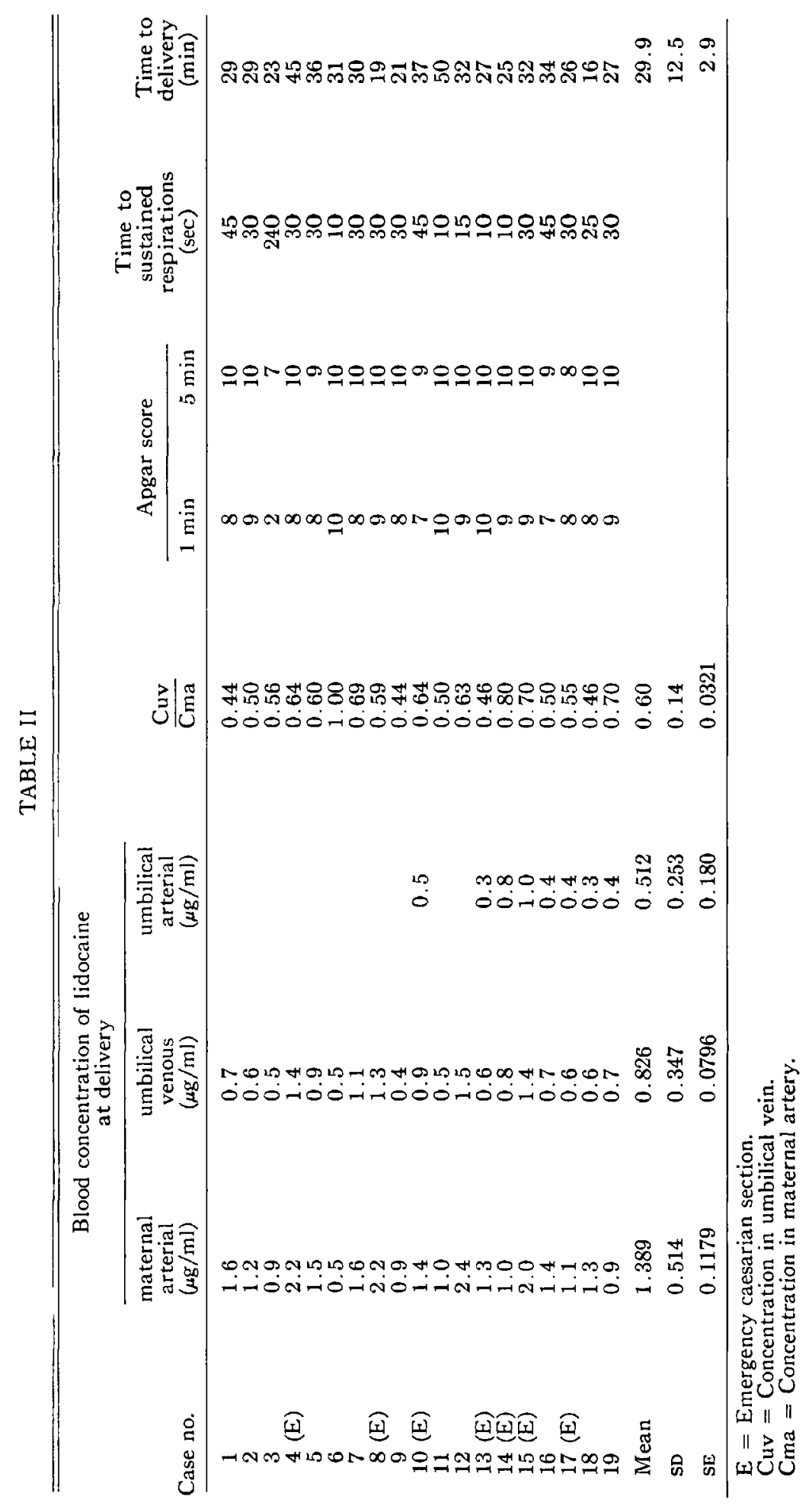


arterial lidocaine concentration is significantly higher than the umbilical venous lidocaine concentration ( $p=<.001$ ). In seven of eight cases, the umbilical arterial lidocaine concentration was less than the umbilical venous concentration. In the remaining case the umbilical venous and arterial concentrations were equal.

Figure 1 illustrates the direct relationship between the maternal arterial and umbilical venous lidocaine concentrations. The ratio of the concentration of lidocaine in the umbilical vein to the concentration in the maternal artery is 0.60

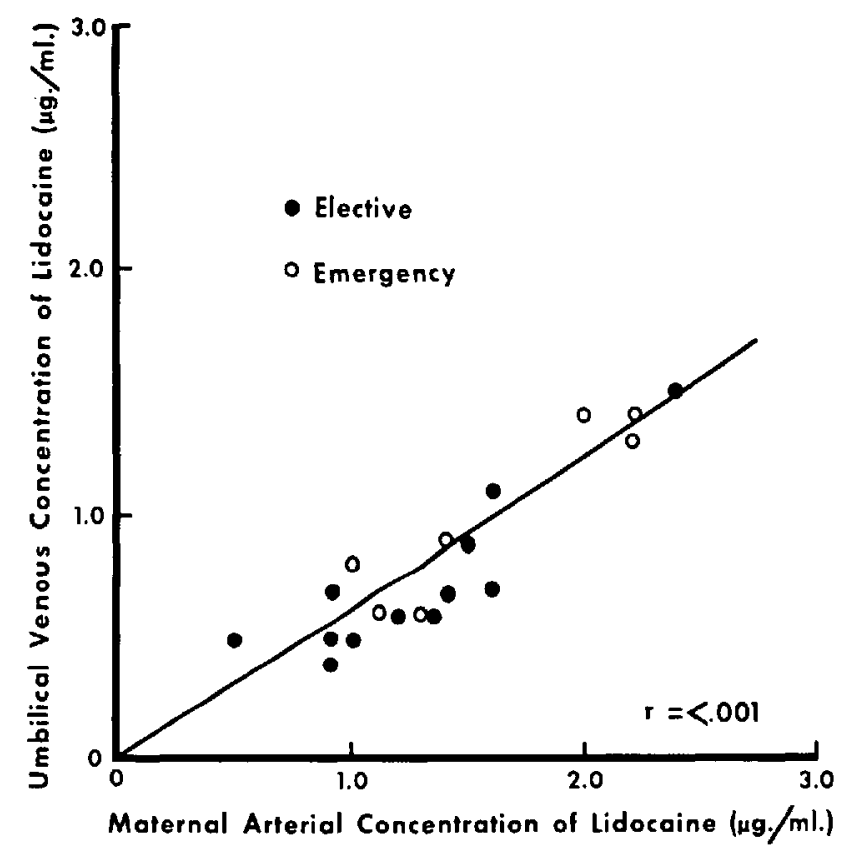

Figure 1. Umbilical venous concentration of lidocaine $(\mu \mathrm{g} / \mathrm{ml})$ plotted against maternal arterial concentration of lidocaine $(\mu \mathrm{g} / \mathrm{ml}) ; r=<.001$.

( $\mathrm{SE}= \pm 0.321$ ). This ratio increased slightly as the time from the epidural injection of lidocaine to delivery increased $(r=<.001)$. This is illustrated in Figure 2.

The height of the sensory block at the time of delivery varied between the second and sixth thoracic dermatomes.

Nine of the nineteen mothers experienced hypotension in varying degree within five minutes of epidural blockade. None exhibited signs of central nervous system toxicity due to the local analgesics.

The Apgar ratings and the time to sustained respiration are given in Table II. The infant born to the diabetic mother (case 3) was obviously depressed, the Apgar ratings at one and five minutes being 2 and 7 respectively. The time to sustained respirations was 240 seconds. Table III summarizes this particular infant's blood gas analyses. 


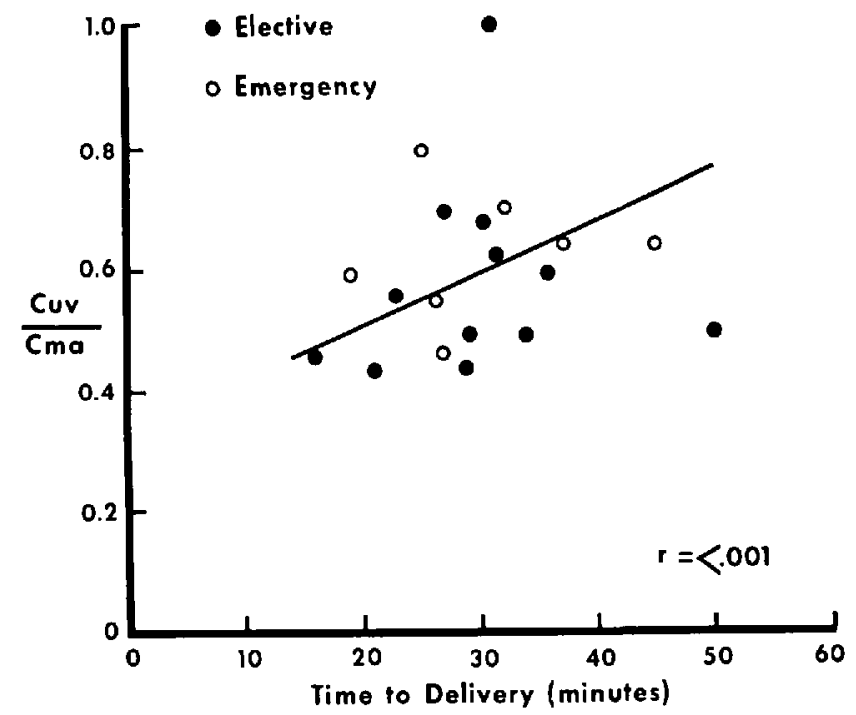

Figure 2. Ratio of lidocaine concentration in the umbilical vein (uv) to the concentration in the maternal artery (ma), plotted against time to delivery; $r=<.001$.

TABLE III

INFANT IN CASE 3

\begin{tabular}{|c|c|c|}
\hline & Umbilical vein & Umbilical artery \\
\hline $\begin{array}{l}\mathrm{Po}_{2}(\mathrm{~mm} \mathrm{Hg}) \\
\mathrm{O}_{2} \mathrm{Sat}^{\prime} \mathrm{n}(\%) \\
{\left[\mathrm{H}^{+}\right](\mu \mathrm{mEq} / \mathrm{L})} \\
\mathrm{PcO}_{2}(\mathrm{~mm} \mathrm{Hg}) \\
\text { Base excess } \\
\text { Standard bicarbonate } \\
\text { Blood lactate (mg \%) }\end{array}$ & $\begin{array}{r}21.5 \\
39 \\
74.1 \\
43.7 \\
-15.8 \\
13.7 \\
49.5\end{array}$ & $\begin{array}{r}7.5 \\
9 \\
89.1 \\
56.3 \\
-17.1 \\
12.4 \\
55.4\end{array}$ \\
\hline
\end{tabular}

\section{Discussion}

The important clinical aspects of this study are the relatively low maternal and foetal blood lidocaine concentrations. These were accompanied by delivery of vigorous infants, with the exception of case 3 , and a minimum of maternal complications. The only maternal complication was the occurrence of hypotension in 47 per cent of the mothers. All patients were comfortable once the sensory blockade was complete, or the hypotension treated.

The reasons for low maternal local anaesthetic requirements at term are not yet established, but several theories have been put forth. ${ }^{12}$ During active labour the pressure changes accompanying uterine contractions are transmitted to the epidural space, possibily increasing the spread of anaesthetic solutions throughout the epidural area. During pregnancy, the vascularity of the meninges may be 
increased, thus facilitating penetration of the meninges by local analgesic solutions and allowing blockade of a greater number of nerves than would occur in a non-pregnant female. Epidural vascular engorgement during elective caesarian section may be caused by the weight of the pregnant uterus partially obstructing the inferior vena cava, and diverting blood into the epidural veins. ${ }^{13,14}$ The resulting venous distension is a space-occupying phenomenon and might cause a wider distribution of a local analgesic.

Two per cent lidocaine with epinephrine 1:200,000 was used routinely in this series. The use of a vasoconstrictor and a low initial dose of the local analgesic agent may account for the low maternal lidocaine concentration at delivery. The mean maternal lidocaine concentration of $1.39 \mu \mathrm{g} / \mathrm{ml}(\mathrm{SE} \pm 0.1179)$ at delivery is approximately 50 per cent of that noted by Morishima ${ }^{1}$ and is somewhat less than the concentration found by Epstein. ${ }^{2}$ Since epinephrine decreases uterine contractions, ${ }^{15}$ some clinicians may object to this practice. However, in the concentrations we employed, it is doubtful whether there is a sufficient maternal blood concentration of epinephrine to depress uterine contractions. Further, since these patients were to have a caesarian section, the depression of uterine contractions in the seven emergency cases would be of no obstetrical concern.

As previously noted, none of the patients in this series exhibited signs of lidocaine toxicity. Bromage and Robson ${ }^{16}$ found that patients showed signs of cerebral irritability when blood concentrations approached $10 \mu \mathrm{g} / \mathrm{ml}$; while Foldes ${ }^{17}$ considered the toxic concentration to be approximately $5 \mu \mathrm{g} / \mathrm{ml}$. The highest concentration obtained at delivery in our series was $2.4 \mu \mathrm{g} / \mathrm{ml}$, well within the safe range.

The low blood concentrations of lidocaine found in the umbilical vein and artery of the infant (Table II) are further evidence of the safety of the anaesthetic technique. These figures are less than the $1.90 \mu \mathrm{g} / \mathrm{ml}$ and $1.42 \mu \mathrm{g} / \mathrm{ml}$ which Morishima ${ }^{1}$ obtained for the umbilical vein and artery respectively. The concentration of lidocaine hydrochloride in the umbilical vein was less than the $1.6 \mu \mathrm{g} / \mathrm{ml}$ found by Epstein. ${ }^{2}$

Since the umbilical vein concentration is directly related to the maternal blood concentration (Fig. 1), the relatively low foetal concentrations of lidocaine in this series are presumably a reflection of the initial total dose of the agent and the resultant low maternal concentration of lidocaine.

The mean ratio between the lidocaine concentration in the umbilical vein and in the maternal artery was $0.60(\mathrm{sE}= \pm .0321)$; that is, the umbilical vein concentration was 60 per cent of the maternal arterial concentration. This is in agreement with Shnider, ${ }^{18}$ who found that infant blood concentrations were 30 to 40 per cent less than maternal concentrations. It is worth noting that this ratio increases with time, indicating equilibration of lidocaine across the placenta.

A further explanation of the differences in local anaesthetic concentrations between this study and others ${ }^{1,2}$ may be the physical characteristics of the local analgesic agents employed. The transfer of drugs across the placenta has been compared to the transfer of drugs across the blood brain barrier; two of the important factors being the lipoid solubility and the degree of ionization of the drug. ${ }^{19,20}$ The $\mathrm{pKa}$ values for lidocaine and mepivacaine are 7.80 and 7.65 
respectively, ${ }^{21}$ indicating that lidocaine ionizes more readily at normal body $\mathrm{pH}$ and is therefore less favoured in its passage across the placenta. On the other hand, the water/lipoid distribution ratios

$$
\mathrm{K}=\frac{\text { aqueous (hydrochloride salt) }}{\text { oleyl alcohol }}
$$

for mepivacaine and lidocaine are 0.15 and 0.08 respectively, ${ }^{21}$ indicating that lidocaine is more lipophilic than mepivacaine and is thus favoured for placental passage. Transfer across the placenta varies inversely with the molecular weight of the drug, those with molecular weights less than 600 passing easily. ${ }^{22}$ The similarity of the molecular weights of lidocaine and mepivacaine (270.8 and 282.8 respectively) is unlikely to give an advantage to either drug. Consequently, it is difficult to state from physical principles which drug is more likely to pass across the placental barrier.

Another possible source of difference between this series and others ${ }^{1,2}$ may be the method of estimating local analgesic concentrations. Both Morishima ${ }^{1}$ and Epstein $^{2}$ used the methyl orange technique. ${ }^{23,24}$ The standard error in Morishima's modified technique ${ }^{24}$ and the one used to determine lidocaine concentrations in this series ${ }^{9}$ are similar, whereas the methodology used by Epstein ${ }^{23}$ lacks the sensitivity of gas chromatography.

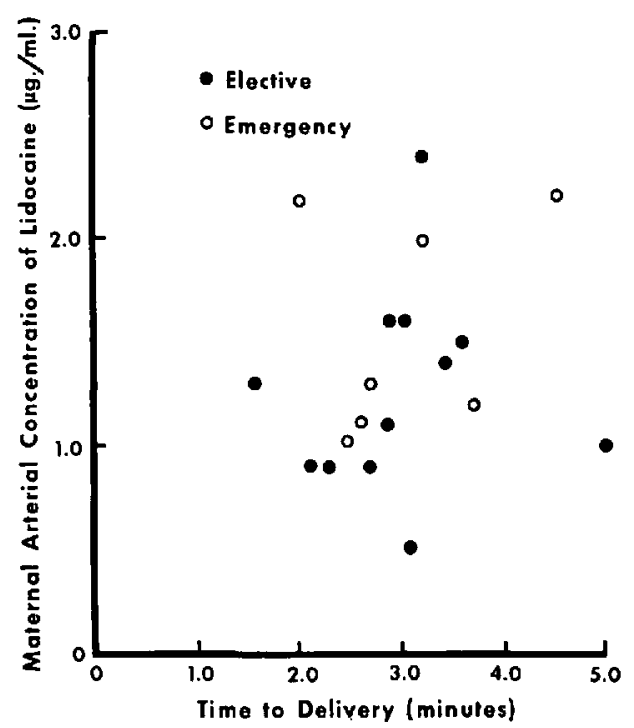

Figure 3. Maternal arterial concentration of lidocaine $(\mu \mathrm{g} / \mathrm{ml})$ plotted against the time to delivery (minutes).

Peak maternal lidocaine concentrations appeared to be at 30 to 35 minutes after the administration of the local anaesthetic agent (Fig. 3). This is not necessarily the time of maximum concentrations in each case, as we did not attempt to determine the highest blood concentration in each patient. Bromage 
and Robson, ${ }^{16}$ using 2 per cent lidocaine with 1:200,000 epinephrine, found peak blood concentrations to be $23( \pm 8$ ) minutes after epidural injection. The intention was to observe the drug concentrations at the time of delivery, which was dictated by the rapidity of the onset of the sensory blockade, the ease or difficulty of the particular operating situation, and the individual speed of the surgeon. Owing to the low lidocaine concentrations generally, we would not advocate the selection of a specific time for delivery; rather, we would wait for the onset of an adequate blockade.

In seven out of eight cases, the umbilical arterial blood concentrations of lidocaine were less than the umbilical venous blood concentrations. This difference cannot be accounted for by liver metabolism, since it appears that the metabolism of local anaesthetics is not accomplished by the foetal liver. ${ }^{25,26}$ Tissue and extracellular space distribution of the local anaesthetic may account for the lower umbilical arterial concentration. ${ }^{18}$ Umbilical arterial blood has passed through the liver, and has been diluted with blood from the abdominal viscera and the pulmonary veins. ${ }^{27}$ Therefore it is representative of blood which has circulated throughout the foetus, during which time there has been tissue uptake and dilution to account for a lower lidocaine concentration than that in the umbilical vein.

Nine of the nineteen patients in this series developed hypotension following epidural blockade. This problem was anticipated, and treated with left uterine displacement in those patients in whom it developed. If this manoeuvre failed to return the blood pressure to normal levels, methamphetamine $5 \mathrm{mg}$ was injected intravenously. The occurrence of hypotension and its treatment did not clinically affect the infants born to these women.

\section{SUMMARY}

Two per cent lidocaine with 1:200,000 epinephrine was used for lumbar epidural analgesia in nineteen caesarian sections. Maternal and foetal blood lidocaine concentrations were obtained. Maternal uptake, placental transmission, and foetal metabolism of lidocaine are discussed.

\section{ACKNOWLEDGMENTS}

We wish to thank Astra Pharmaceuticals, Worcester, Massachusetts, for determining lidocaine concentrations in blood.

\section{REFERENCES}

1. Monishma, H. O.; Daniel, S. S.; Finster, M.; Poppens, P. J.; \& James, L, S. Transmission of Mepivacaine Hydrochloride (Carbocaine) across the Human Placenta. Anesthesiology, 27: 147 (1966).

2. Epstein, Burton S.; Bannerjee, Sheela G.; \& Coakley, Charles S. Passage of Lidocaine and Prilocaine across the Placenta. Anesth, \& Analg. 47; 223 (1968).

3. - - Comparative Effects of Prilocaine and Lidocaine during Peridural Anaesthesia for Obstetrics. Anesth. \& Analg. 47: 228 (1968).

4. Usublaga, J. E.; La Iuppa, M.; Moya, F.; WIEInski, J. A.; \& Velazco, R. Passage of Procaine Hydrochloride and Para-aminobenzoic Acid across the Human Placenta. Am. J. Obst. \& Gynec. 100: 918 (1968). 
5. Sinclatr, John C.; Fox, Howard A.; Lentz, Joseph F.; Fuld, Gilbert L.; \& Murphy, JEROME. Intoxication of the Fetus by a Local Anesthetic. New England J. Med. 273: 1174 (1965).

6. Rosefsey, Jonathan, B. \& Petensiel, Mel. E. Perinatal deaths Associated with Mepivacaine Paracervical-block Anaesthesia in Labor. New England J. Med. 278: 530 (1968).

7. Nyirjesy, I.; Hawks, B. L.; Herbert, J. E.; Hopwood, H. G.; \& Falls, H. C. Hazards of Use of Paracervical Block Anaesthesia in Obstetrics. Am. J. Obst. \& Cynec. 87: 231 (1963).

8. Bromage, P. R. Continuous Lumbar Epidural Analgesia for Obstetrics. C.M.A.J. 85: $1136(1961)$.

9. Keenaghan, Joseph B. The Determination of Lidocaine and Prilocaine in Whole Blood by Gas Chromatography. Anesthesiology. 29: 110 (1968).

10. Apgar, Virginia. A Proposal for a New Method of Evaluation of the Newborn Infant. Anesth. \& Analg. 32: 260 (1953).

11. Apgar, V.; Holaday, D. A.; James, L. S.; Weisgrot, I. M.; Prunce, C. E.; \& Weiss, I. Comparison of Regional and General Anaesthesia in Obstetrics. J.A.M.A. 165: 2155 (1957).

12. Bromage, P. R. The Spread of Analgesic Solutions in the Epidural Space and Their Site of Action. Brit. J. Anaes. 34: 161 (1962).

13. Kerr, M. G.; ScotT, D. B.; \& SAMued, E. Studies of the Inferior Vena Cava in Late Pregnancy. Brit. Med. J. 1: 532 (1964).

14. Samued, E.; Scott, D. B.; \& Kerr, M. G. The Inferior Vena Cavagram in Pregnancy. Proc. Roy. Soc. Med. 57: 32 (1964).

15. Goodman, Lours S. \& Gilman, Alfred. The Pharmacological Basis of Therapeutics. 3rd ed., New York: Macmillan, p. 491.

16. Bromage, P. R. \& Robson, J. Gordon. Concentrations of Lignocaine in the Blood after Intravenous, Intramuscular, Epidural, and Endotracheal Administration. Anaesthesia. 16: 461 (1961).

17. Foldes, F. F.; Mallox, R.; McNall, P. G.; \& Kaukal, L. R. Comparison of Toxicity of Intravenously Given Local Anesthetic Agents in Man. J.A.M.A. 172: 1493 (1960).

18. Shniber, S. M. Local Anaesthetics and the Neonate. New England J. Med. 274: 226 (1966).

19. Seeds, A. E. Placental Transfer in Intrauterine Development. Philadelphia: Lea \& Febiger (1968), p. 103.

20. Yaffe, Summer J. Some Aspects of Perinatal Pharmacology. Ann. Rev. Med. 17: 213 (1966).

21. Sterling-Winthrop Research Institute. Personal communication.

22. Moxa, F. Mechanisms of Drug Transfer Across the Placenta, with Particular Reference to the Chemotherapeutic Drugs. Antimicrobial Agents \& Chemotherapy. 5: 1051 (1965).

23. Sung, C. \& Truant, A. P. The Physiological Deposition of Lidocaine and Its Comparison in Some Respects with Procaine. J. Pharmacol. Exper. Therap. 112: 432 (1954)

24. Daniel, Salha, S. \& Morishima, H. O. The Estimation of Mepivacaine Hydrochloride in Biological Fluids. Anesthesiology. 28: 924 (1967).

25. Fouts, J. R. \& Adamson, R. H. Drug Metabolism in the Newborn Rabbit. Science. 129: 897 (1959).

26. Adamsons, K. JR. \& Joelsson, I. The Effects of Pharmacological Agents upon the Fetus and Newborn. Am. J. Obst. \& Gynec. 96: 437 (1966).

27. Moxa, F. \& Thorndike, V. The Effects of Drugs Used in Labour on the Fetus and Newborn. Clin. Pharmacol. \& Therap. 4: 628 (1963). 